\title{
Abnormalities of right ventricular long axis function after atrial repair of transposition of the great arteries
}

\author{
G P Derrick, M Josen, M Vogel, M Y Henein, E A Shinebourne, A N Redington
}

\begin{abstract}
Background-While volume derived global indices of right ventricle (RV) function are frequently abnormal after the Mustard procedure, the mechanism for these abnormalities is poorly understood. RV muscle fibres are predominantly arranged longitudinally and thus indices derived in the long axis may better describe RV function.

Methods-20 survivors of the Mustard operation were studied (age 7.8-37.3 years, median 14.2 years). Long axis recordings from the apical four chamber view were obtained with the $M$ mode cursor positioned through the lateral angle of the tricuspid valve annulus. $M$ mode traces were recorded on paper and later digitised to derive total atrioventricular ring excursion, peak lengthening rate, and peak shortening rate. These data were averaged and compared with control data for the normal RV and left ventricle (LV).

Results-RV total atrioventricular ring excursion was lower than that for the RV $(p<0.0001)$ or LV $(p<0.005)$ of controls. Peak lengthening rate was lower than the normal RV $(p<0.0001)$ and LV ( $p<0.0001)$ rates. Furthermore, peak shortening rate was less than that of normal RV $(\mathrm{p}<0.0001)$ and normal LV $(\mathrm{p}<0.005)$ controls.

Conclusion-Systemic RV long axis function is notably reduced compared with that of either the normal subpulmonary RV or the systemic LV. This presumably reflects the response of the predominantly longitudinally arranged myocardial fibres to increased afterload. However, such measurements may provide a more sensitive marker for progressive changes in global function during long term follow up.

(Heart 2001;86:203-206)
\end{abstract}

Keywords: Mustard procedure; right ventricular function; transposition of the great arteries

Atrial diversion procedures $^{12}$ revolutionised the outlook for patients with transposition of the great arteries. Although these procedures have largely been superseded by the arterial switch operation, ${ }^{3}$ there is a large number of teenaged and adult survivors of both the Mustard and the Senning operations under long term follow up.

Impaired function of the systemic right ventricle (RV) has been inferred from the almost universal finding of increased RV volumes and reduced ejection fraction in mid term survivors of atrial diversion procedure. The reported incidence of ventricular dysfunction is variable, ${ }^{4-6}$ and this probably relates to difficulties with the assessment of global function. Our own group has previously shown that segmental wall motion abnormalities are common in these patients before and after the Mustard procedure and that they are related to global RV dysfunction.?

Some patients develop progressive systemic ventricular dysfunction and may be considered for further surgery, either a late arterial switch or cardiac transplantation, ${ }^{8}$ but prediction of failure in these patients is difficult. Conventional assessment of global systemic left ventricle (LV) function is based on analysis of the basal component, influenced mainly by the deep circumferential myocardial fibre layer. ${ }^{9}$ Myocardial fibres also run in a longitudinal fashion in the subendocardial and subepicardial planes of the LV. Analysis of these myocardial fibres is sensitive for showing $\mathrm{LV}$ disease. ${ }^{10}$ The majority of RV myocardial fibres originate at the apex of the heart and insert into the right atrioventricular junction, such that the main bulk of the RV myocardium is composed of longitudinally arranged fibres. ${ }^{9}$ Thus the analysis of longitudinal myocardial fibres may be especially relevant to the description of systemic RV function.

\section{Methods}

The Mustard operation, with the modification of Quaegebeur and Brom, ${ }^{11}$ was the preferred operation for transposition of the great arteries performed at the Royal Brompton Hospital during the era preceding the introduction of the arterial switch. We prospectively recorded echocardiographic data from these patients attending the outpatient clinic. Patients were excluded if they did not have resting sinus rhythm or were shown to have significant baffle obstruction. Control data were drawn from subjects matched for age and sex, identified retrospectively from the echocardiography department records. These subjects had attended for investigation of a cardiac murmur or as part of a family screening programme and were found to have normal echocardiographic examinations.

\section{ECHOCARDIOGRAPHIC EVALUATION OF} VENTRICULAR FUNCTION

Echocardiograms were performed with patients lying in the semilateral left supine position. A $3.5-5.0 \mathrm{MHz}$ probe linked to a 
Table 1 Demographic data for study patients

\begin{tabular}{|c|c|c|c|c|c|c|c|c|}
\hline$I D$ & $\operatorname{Sex}$ & $\begin{array}{l}\text { Age at operation } \\
\text { (years) }\end{array}$ & $\begin{array}{l}\text { Age at study } \\
\text { (years) }\end{array}$ & $\begin{array}{l}\text { Height } \\
(\mathrm{cm})\end{array}$ & $\begin{array}{l}\text { Weight } \\
(\mathrm{kg})\end{array}$ & Baffles & Other lesion & Catheter intervention \\
\hline 1 & $M$ & 1.1 & 7.8 & 134 & 27.6 & AutP & \multirow{8}{*}{ SubPS; vascular ring } & \multirow{10}{*}{ BD 1989, 1993} \\
\hline 2 & $\mathrm{~F}$ & 0.4 & 8.1 & & 21.6 & AutP & & \\
\hline 3 & $\mathrm{~F}$ & 0.6 & 8.5 & 136 & 29.2 & AutP & & \\
\hline 4 & $M$ & 0.5 & 9.3 & 112 & 18.4 & AutP & & \\
\hline 5 & $\mathrm{~F}$ & 0.7 & 10.6 & 138.5 & 29.3 & BovP & & \\
\hline 6 & M & 0.2 & 11.0 & 140 & 29.0 & Dura & & \\
\hline 7 & $M$ & 0.7 & 12.9 & 167 & 54.2 & NR & & \\
\hline 8 & $M$ & & 13.2 & & & & & \\
\hline 9 & $M$ & 0.6 & 13.3 & 149 & 43.2 & Dacron & \multirow{6}{*}{ VSD, mild subPS } & \\
\hline 10 & $M$ & 1.6 & 14.5 & 170 & 50.8 & Dura & & \\
\hline 11 & $M$ & 0.4 & 14.8 & 158 & 49.2 & Dura & & BD IVC 1985 \\
\hline 12 & $\mathrm{~F}$ & 0.5 & 15.0 & 162 & 67.2 & BovP & & BD IVC 1991, 1997 \\
\hline 13 & $M$ & 1.0 & 15.4 & 161 & 54.1 & BovP & & BD IVC 1991 \\
\hline 14 & $\mathrm{~F}$ & 1.1 & 16.7 & 164 & 63.1 & Dura & & \multirow{5}{*}{ BD IVC 1994} \\
\hline 15 & $M$ & 1.8 & 16.8 & 171.5 & 68.8 & Dacron & & \\
\hline 16 & M & 1.9 & 19.4 & 161 & 48.1 & Dacron & VSD & \\
\hline 17 & $M$ & 2.4 & 22.2 & 160 & 59.2 & Dacron & VSD & \\
\hline 18 & $M$ & 10.6 & 25.1 & 160 & 42.6 & Dura & \multirow{5}{*}{$\begin{array}{l}\text { VSD } \\
5\end{array}$} & \\
\hline 19 & $\mathrm{~F}$ & 5.4 & 31.4 & 166 & 66.9 & Dacron & & \multirow{4}{*}{$\begin{array}{l}\text { BD \& stent IVC } 1997 \\
6\end{array}$} \\
\hline 20 & $\mathrm{~F}$ & 10.7 & 37.4 & 163 & 50.8 & Dacron & & \\
\hline $\mathrm{n}$ & M13, F7 & 19 & 20 & 18 & 19 & & & \\
\hline Mean & & 2.2 & 16.2 & 154.1 & 46.0 & & & \\
\hline
\end{tabular}

AutP, autologous pericardium; BD, balloon dilatation; BovP, bovine pericardium; Dura, dura mater; ID, patient number; IVC, inferior vena cava; NR, not recorded; SubPS, subpulmonary stenosis; VSD, ventricular septal defect.

Hewlett-Packard Sonos 2000 echocardiography system (Agilent Technologies, Palo Alto, California) was used in all cases. Long axis $M$ mode recordings of the $\mathrm{RV}$ were made simultaneously with superimposed ECG, respiratory trace, and phonocardiogram. M mode recordings were taken from the apical four chamber view with the cursor positioned through the lateral angles of the tricuspid and mitral valves.

The resulting $M$ mode traces were recorded onto a continuous paper strip at $100 \mathrm{~mm} / \mathrm{s}$ and later digitised and analysed using a custom made computerised system to derive total excursion, peak shortening, and peak lengthening rates. For each $\mathrm{M}$ mode recording two or where possible three heartbeats were digitised and mean values were calculated.

STATISTICAL ANALYSIS

Unpaired $t$ test was used to assess differences between the patients and controls and the null hypothesis was rejected if $\mathrm{p}<0.05$.

\section{Results}

Table 1 shows the demographic details of the study patients. There were 13 male and seven female study patients (median age 14 years), and 13 male and seven female control subjects

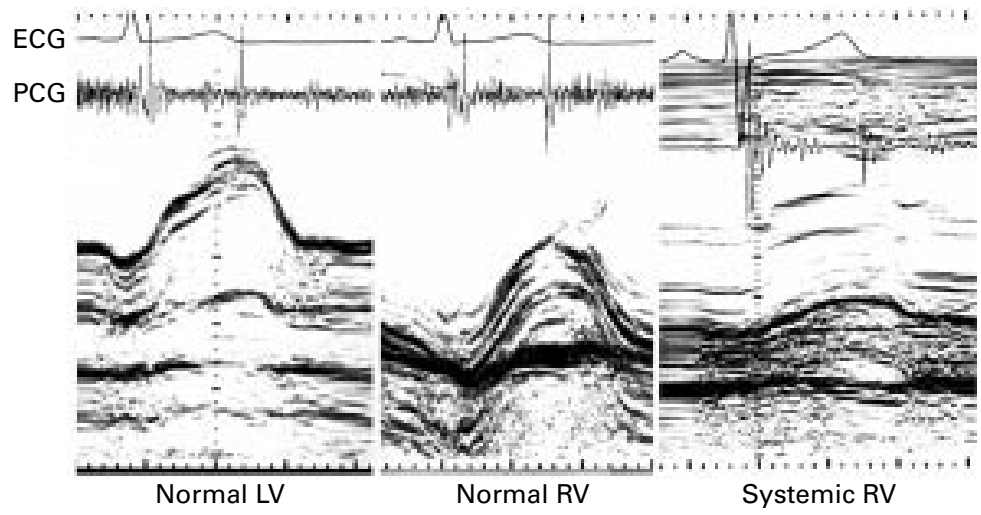

Figure 1 Sample $M$ mode echocardiographic traces in the long axes of the systemic right ventricle (RV), the normal left ventricle (LV), and the normal RV. PCG, phonocardiogram. (median age 13 years). All patients had undergone Rashkind balloon atrial septostomy in the newborn period. The median age at operation was 8 months. Five patients had surgery for additional lesions at the time of the Mustard repair and six patients required catheter intervention on at least one occasion for intra-atrial pathway stenosis.

Figure 1 shows sample $M$ mode traces in the long axis of the systemic RV, and the normal LV and RV. Table 2 shows their absolute values of total excursion, peak shortening rate and peak lengthening rate of the atrioventricular valve ring in the long axis of the systemic RV following Mustard repair, also expressed as a percentage of the matched controls.

Total excursion of the systemic RV was less than the excursion of the normal subpulmonary RV in 20 of 20 patients and less than the excursion of the normal systemic LV in 17 of 20. Peak shortening velocity of the systemic RV was less than that of the subpulmonary RV in 19 of 20 patients, and less than that of the normal systemic LV in 15 of 21 patients. Peak lengthening rate in the systemic RV was less than that in the subpulmonary LV in all patients and less than that of the systemic LV in 19 of 20 patients.

There were no relations between indices and history of additional cardiac surgical procedures, catheter intervention, or age at repair. However, there was a weak but significant correlation between the age of the patient and peak shortening rate of the systemic RV, when expressed as a percentage of both the normal LV peak shortening rate $(\mathrm{p}<0.05)$ and normal $\mathrm{RV}$ peak shortening rate $(\mathrm{p}<0.05)$. Total excursion of the systemic ventricle as a percentage of normal LV total excursion was also correlated with the age of the patient $(\mathrm{p}<0.05)$.

\section{Discussion}

Ejection fraction has traditionally been the means of assessing systemic ventricular function in patients with a systemic circulation dependent on a morphological RV. Various 
Table 2 Right ventricular long axis indices versus control data

\begin{tabular}{|c|c|c|c|c|c|c|c|c|c|c|c|}
\hline \multirow[b]{3}{*}{$I D$} & \multirow[b]{3}{*}{ Sex } & \multirow{3}{*}{$\begin{array}{l}\text { Age } \\
\text { (years) }\end{array}$} & & & & \multicolumn{6}{|c|}{ Age and sex matched controls } \\
\hline & & & \multicolumn{3}{|c|}{ Measured RV } & \multicolumn{3}{|c|}{ Percentage of control $R V$} & \multicolumn{3}{|c|}{ Percentage of control LV } \\
\hline & & & $T E$ & PSR & $P L R$ & $T E$ & $P S R$ & $P L R$ & $T E$ & $P S R$ & $P L R$ \\
\hline 1 & $M$ & 7.8 & 1.0 & 4.4 & 5.2 & 96.0 & 108.7 & 58.9 & 76.6 & 97.5 & 48.7 \\
\hline 2 & $\mathrm{~F}$ & 8.1 & 1.6 & 7.5 & 7.2 & 63.2 & 64.0 & 51.1 & 125.6 & 150.0 & 80.7 \\
\hline 3 & $\mathrm{~F}$ & 8.5 & 1.1 & 4.9 & 3.9 & 42.7 & 41.8 & 28.0 & 85.0 & 97.9 & 44.2 \\
\hline 4 & M & 9.3 & 0.8 & 3.6 & 5.0 & 55.3 & 52.3 & 61.5 & 55.3 & 40.4 & 38.1 \\
\hline 5 & $\mathrm{~F}$ & 10.6 & 1.9 & 8.9 & 12.2 & 76.1 & 76.0 & 86.7 & 151.2 & 178.1 & 136.8 \\
\hline 6 & M & 11.0 & 1.5 & 7.7 & 9.3 & 51.6 & 58.4 & 57.4 & 92.9 & 102.2 & 76.6 \\
\hline 7 & M & 12.9 & 1.2 & 6.7 & 4.6 & 42.3 & 51.2 & 28.4 & 76.2 & 89.6 & 37.8 \\
\hline 8 & M & 13.2 & 1.2 & 5.4 & 5.4 & 42.0 & 41.1 & 33.2 & 75.7 & 71.9 & 44.2 \\
\hline 9 & M & 13.3 & 1.2 & 6.7 & 6.8 & 40.7 & 51.0 & 41.9 & 73.3 & 89.2 & 55.9 \\
\hline 10 & M & 13.5 & 1.3 & 6.3 & 7.9 & 45.6 & 47.6 & 48.6 & 82.2 & 83.3 & 64.7 \\
\hline 11 & M & 14.8 & 1.2 & 4.9 & 5.3 & 59.7 & 41.9 & 48.5 & 75.2 & 43.6 & 40.5 \\
\hline 12 & $\mathrm{~F}$ & 15.0 & 1.3 & 6.6 & 5.0 & 61.0 & 79.2 & 48.5 & 100.0 & 123.5 & 50.0 \\
\hline 13 & $M$ & 15.4 & 0.8 & 3.5 & 5.7 & 42.6 & 30.1 & 52.2 & 53.6 & 31.4 & 43.6 \\
\hline 14 & $\mathrm{~F}$ & 16.7 & 1.2 & 6.0 & 9.0 & 55.2 & 72.5 & 87.3 & 90.5 & 112.9 & 90.0 \\
\hline 15 & $M$ & 16.8 & 1.5 & 8.1 & 9.4 & 55.8 & 60.0 & 51.1 & 84.1 & 77.0 & 66.7 \\
\hline 16 & M & 19.4 & 1.0 & 4.7 & 7.1 & 31.1 & 35.7 & 58.1 & 64.1 & 83.3 & 56.7 \\
\hline 17 & M & 22.2 & 0.9 & 4.5 & 4.7 & 28.3 & 35.8 & 37.0 & 40.3 & 48.3 & 37.7 \\
\hline 18 & M & 25.1 & 1.6 & 7.3 & 11.9 & 50.3 & 57.9 & 93.7 & 71.7 & 78.1 & 95.5 \\
\hline 19 & $\mathrm{~F}$ & 31.4 & 1.2 & 3.5 & 7.4 & 53.0 & 21.0 & 25.7 & 56.7 & 31.5 & 45.5 \\
\hline 20 & $\mathrm{~F}$ & 37.4 & 1.1 & 4.9 & 7.1 & 52.0 & 29.2 & 24.9 & 55.7 & 43.8 & 44.0 \\
\hline $\mathrm{n}$ & & & & & & 20 & 20 & 20 & 20 & 20 & 20 \\
\hline Mean & & & & & & 52.2 & 52.8 & 51.1 & 79.3 & 83.7 & 59.9 \\
\hline $\mathrm{p}$ Value & & & & & & $<0.0001$ & $<0.0001$ & $<0.0001$ & $<0.0005$ & $<0.005$ & $<0.0001$ \\
\hline
\end{tabular}

LV, left ventricle; PLR, peak lengthening rate; PSE, peak shortening rate; RV, right ventricle; TE, total excursion.

methods of assessment have been described that use echocardiography, angiography, first pass or gated radionuclide studies, and latterly magnetic resonance imaging. The correlations between the different methods of ejection fraction estimation are, however, relatively weak, ${ }^{12}$ reflecting the difficulties in applying accurate endocardial border detection techniques to the entirety of the complex geometric shape of the RV.

Nonetheless, most published data show increased systemic RV end diastolic volume and reduced ejection fraction after intra-atrial repair of transposition. Our previous study showed that reduced global function was related to the presence of regional abnormalities of RV wall motion, which, in turn, appeared to be present before the Mustard procedure. ${ }^{7}$ There is other evidence that the substrate for later global dysfunction exists, in the form of myocardial damage, before the Mustard procedure..$^{13} 14$

Clearly, though, there are no "normal" values of RV ejection fraction under these circumstances. Furthermore, it must remain uncertain whether altered ejection fraction, our previous findings of increased globularity of the $\mathrm{RV}$, and the data presented here simply reflect the chronic response of the RV to its loading conditions. Ejection fraction, for example, can remain remarkably constant over long term follow up, ${ }^{515}$ and prediction of RV failure is difficult. In the normal RV and LV, total excursion of the atrioventricular valve annulus is well correlated to ejection fraction. ${ }^{16}$ However, one previous study of tricuspid annular plane systolic excursion after Mustard operation showed no correlation with RV ejection fraction. ${ }^{12}$ This should not undermine the utility of this method of assessment since ejection fraction itself may be a poor indicator of dysfunction in this group of patients. Long axis indices in the normal heart show an age related decline in systolic and diastolic atrioventricular valve ring velocity. ${ }^{17}$ Our data show a correlation between peak shortening rate, corrected to the matched control, and the age of the patient. Thus, peak shortening rate in the long axis of the systemic RV may decline faster than in the normal population over time.

We have recently shown that load independent indices of RV function respond appropriately to inotropic stimulation. ${ }^{18}$ Failure to augment stroke volume seems to be the primary abnormality under these circumstances and is related to abnormalities of atrioventricular coupling rather than intrinsic RV contractile failure. While long axis function is not immune to the problems of load dependency, our data showing reduction in diastolic excursion of the systemic atrioventricular ring may provide some insights into these abnormalities of atrioventricular coupling. Indeed it is likely that reduced reservoir function, lack of atrial systolic function, and reduced atrioventricular valve ring motion may all, independently or in co-related fashion, contribute to the abnormal diastolic properties in these patients. It remains to be seen whether longitudinal assessment of RV long axis function is a more sensitive noninvasive method of detecting systolic or diastolic dysfunction in these patients, but the predominantly longitudinally arranged myocardial fibres of the morphological RV make this intuitively a potentially more robust index for monitoring systemic RV function over time.

CONCLUSION

RV function is abnormal after the Mustard procedure. Systolic shortening and diastolic lengthening are both notably reduced compared with that in either the subpulmonary RV or the systemic LV of controls. While systolic abnormalities may be reactive to the chronically raised afterload, the diastolic abnormalities may contribute to the abnormal atrioventricular coupling previously described in these patients. 
Dr Derrick is supported by the British Heart Foundation.

1 Senning A. Surgical correction of transposition of the great vessels. Surgery 1959;45:966-80.

2 Mustard WT. Successful two-stage correction of transposition of the great vessels. Surgery 1964;55:469-72.

3 Jatene AD, Fontes VF, Paulista PP, et al. Successful anatomic correction of transposition of the great vessels. A preliminary report. Arq Bras Cardiol 1975;28:461-4.

4 Graham TPJ, Atwood GF, Boucek RJ, et al. Abnormalities of right ventricular function following Mustard's operation for transposition of the great arteries. Circulation 1975;52 678-84.

5 Wong KY, Venables AW, Kelly MJ, et al. Longitudinal study of ventricular function after the Mustard operation for transposition of the great arteries: a long term follow up. $B r$ Heart f 1988;60:316-23.

6 Hurwitz RA, Caldwell RL, Girod DA, et al. Right ventricular systolic function in adolescents and young adults after Mustard operation for transposition of the great arteries. Am 7 Cardiol 1996;77:294-7.

7 Redington AN, Rigby ML, Oldershaw P, et al. Right Redington AN, Rigby ML, Oldershaw $\mathrm{P}$, et al. Right ventricular function 10 years after the Mustard operation for transposition of the great arteries: analysis of
shape, and wall motion. Br Heart $\mathcal{1} 1989 ; 62: 455-61$

shape, and wall motion. Br Heart f 1989;62:455-61.
Mavroudis C, Backer CL. Arterial switch after failed atrial

8 Mavroudis C, Backer CL. Arterial switch after failed atrial

baffle procedures for transposition of the great arteries. Ann
Thorac Surg 2000;69:851-7.
Rushmer R, Crystal D, Wagner C. The functional anatomy

of ventricular contraction. Circ Res 1952;1:162-70.
10 Henein MY, Anagnostopoulos C, Das SK, et al. Left ventricular long axis disturbances as predictors for thallium ventricular long axis disturbances as predictors for thallium perfusion defects in patients with known peripheral vascu1998;79:295-300.

11 Quaegebeur JM, Brom AG. The trousers-shaped baffle for use in the Mustard operation. Ann Thorac Surg 1978;25: $240-2$.

12 Wilson NJ, Neutze JM, Rutland MD, et al. Transthoracic echocardiography for right ventricular function late after the Mustard operation. Am Heart f 1996;131:360-7.

13 Boucek RJ J., Kasselberg AG, Boerth RC, et al. Myocardial injury in infants with congenital heart disease: evaluation by creatine kinase $\mathrm{MB}$ isoenzyme analysis. Am 7 Cardiol 1982;50:129-35.

14 Jarmakani JM, Canent RVJ. Preoperative and postoperative right ventricular function in children with transposition of the great vessels. Circulation 1974;50:II39-45.

15 Reich O, Vorísková M, Ruth C, et al. Long-term ventricular performance after intra-atrial correction of transposition: performance after intra-atrial correction of transposition:
left ventricular filling is the major limitation. Heart 1997; 78:376-81.

16 Kaul S, Tei C, Hopkins JM, et al. Assessment of right ventricular function using two-dimensional echocardioraphy. Am Heart f 1984:107:526-31.

17 Nilsson B, Bojo L, Wandt B. Influence of body size and age on maximal systolic velocity of mitral annulus motion. Clin Physiol 2000;20:272-8.

8 Derrick GP, Narang I, White PA, et al. Failure of stroke volume augmentation during exercise and dobutamine stress is unrelated to load-independent indexes of right ventricular performance after the mustard operation. Circulation 2000;102:III154-9.

\section{IMAGES IN CARDIOLOGY}

\section{Left atrial myxoma supplied from the right coronary artery}

A 54 year old woman was admitted to hospital because of worsening effort dyspnoea during the previous six months. She was hypercholesterolaemic without any family history of cardiac disease or malignancies. Physical examination revealed a diastolic murmur, ECG was normal, and chest $x$ ray showed signs of moderate pulmonary congestion. Transoesophageal echocardiography showed a large left atrial myxoma $(51 \times 31 \times 37 \mathrm{~mm})$, arising from the atrial septum (arrow) and protruding into the mitral valve orifice during diastole. Coronary angiography was performed to exclude the presence of treatable coronary artery disease. Right coronary artery angiogram revealed a large artery (internal diameter about $2.0 \mathrm{~mm}$ ) that supplied the myxoma (arrow) through neoformed clusters of small tortuous vessels (arrow heads).

The mass was successfully removed by surgical excision of the root of the myxoma and the surrounding interatrial septum followed by closure of the residual septum defect with a Dacron patch. Pathological analysis of the tumour confirmed the clinical diagnosis of left atrial myxoma.
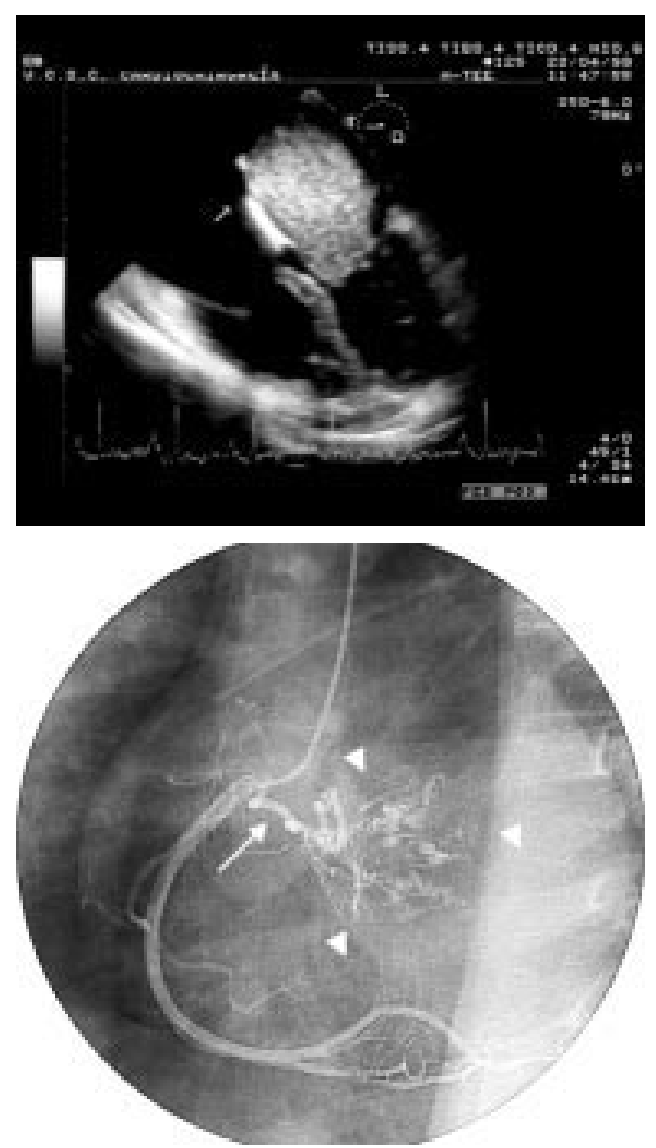